\title{
A Study on the Relationship between Anodic Oxidation and the Thermal Load on the Aluminum Alloy Piston of a Gasoline Engine
}

\author{
Huali Guo*, Yi Liang, Zhilong Zhang and Yuanhua Chen \\ School of Automotive Engineering, Guilin University of Aerospace Technology, Guilin, 541004, China \\ ${ }^{*}$ Corresponding Author: Huali Guo. Email: guohuali@guat.edu.cn
}

Received: 21 June 2021 Accepted: 16 August 2021

\begin{abstract}
In order to analyze the influence of the anodizing process on the thermal load of an aluminum alloy piston, dedicated temperature tests have been carried out using the Hardness Plug method and the results for the anodized piston have been compared with those obtained separately for an original aluminum piston. In addition, numerical simulations have been conducted to analyze the temperature field and thermal stress distribution. Simulations and experiments show that the maximum temperature of the anodized piston is $16.36 \%$ and $5.4 \%$ smaller than that of the original piston under the condition of maximum torque and maximum power, respectively. The thermal stress of the temperature field of both pistons is within $50 \mathrm{Mpa}$, which meets the strength requirements of the material at high temperature. However, the area with significant thermal stress of the anodized piston is significantly smaller than that of the original piston. Combined with the fatigue analysis data, it can be seen that the safety factor of the anodized piston greater than 1.8 is $99.13 \%$. Therefore, adopting the anodizing process not only reduces the piston thermal load, but also helps to extend its life and improve its reliability.
\end{abstract}

\section{KEYWORDS}

Alloy piston; thermal load; anodic oxidation; hardness plug

\section{Introduction}

The internal combustion engine is a machine which can convert thermal energy into mechanical energy [1], and the piston is the main heated part in the internal combustion engine. The thermal load is one of the factors that cause the piston to work abnormally, and the degree of influence of this effect increases with the increase of the strengthening index in the internal combustion engine [2]. Many scholars have used the finite element method to study the temperature field and thermal stress of the piston. However, none of the current studies involved the influence of the piston's anodic oxide layer on the thermal load of the piston. The anodizing technology has been widely used in the surface treatment of alloy aluminum to improve its surface mechanical properties and corrosion resistance. The anodized film itself has high temperature resistance. For comprehensive consideration of the temperature and strength of the piston under different working conditions and analysis of its impact on knocking and lubrication wear, the premise is to analyze the piston temperature field. In this paper, the temperature field of the piston of the gasoline engine was studied by means of the hardness plug temperature test and numerical simulation method. Through the comparison of CAE simulation and experimental test, the thermal load of the anodized piston of the 
engine was studied to comprehensively evaluate whether the improved piston could meet the requirements of engineering applications.

\section{Piston Temperature Field Test and Data Processing}

\subsection{Data Processing of the Tempering Curve of the Hardness Plug}

The piston temperature is usually measured by a hardness plug. The principle is to use a special alloy to produce a permanent hardness change plug after quenching. The surface hardness varies with tempering temperatures. The measurement is done in combination with a hardness tester and other equipment [3]. For the material of the hardness plug, the tempering temperature and hardness change are preferably linear to linear. The material used in this experiment was GCr15 ball bearing steel, and the experimental instrument was a digital micro Vickers hardness tester. For the instrument to work properly, the measuring range was set to $5 \mathrm{HV}$ to $3000 \mathrm{HV}$, the minimum detection unit was $0.025 \mu \mathrm{m}$, the applied load was $300 \mathrm{~N}$, and the load holding time was $10 \mathrm{~s}$ [4]. After quenching, 10 hardness plugs are taken for hardness measurement, and 3 measurement points were taken on each hardness plug. The measured data was shown in Table 1 and Fig. 1.

Table 1: Hardness measurement data table after quenching

\begin{tabular}{lllll}
\hline \multirow{2}{*}{ No. } & \multicolumn{3}{c}{ Actual hardness/(HV) } & Average value \\
\cline { 2 - 4 } & 1 & 2 & 3 & \\
\hline 1 & 813.2 & 823.1 & 832.5 & 822.9 \\
2 & 812.5 & 822.1 & 833.5 & 822.7 \\
3 & 823.6 & 809.2 & 855.1 & 829.3 \\
4 & 823.5 & 826.6 & 812.6 & 820.9 \\
5 & 816.5 & 824.5 & 824.6 & 819.2 \\
6 & 836.5 & 816.3 & 823.5 & 825.4 \\
7 & 831.4 & 815.6 & 824.9 & 824.0 \\
8 & 810.4 & 825.6 & 826.8 & 820.9 \\
9 & 812.6 & 814.6 & 834.5 & 820.6 \\
10 & 815.7 & 835.4 & 828.9 & 826.7 \\
\hline
\end{tabular}

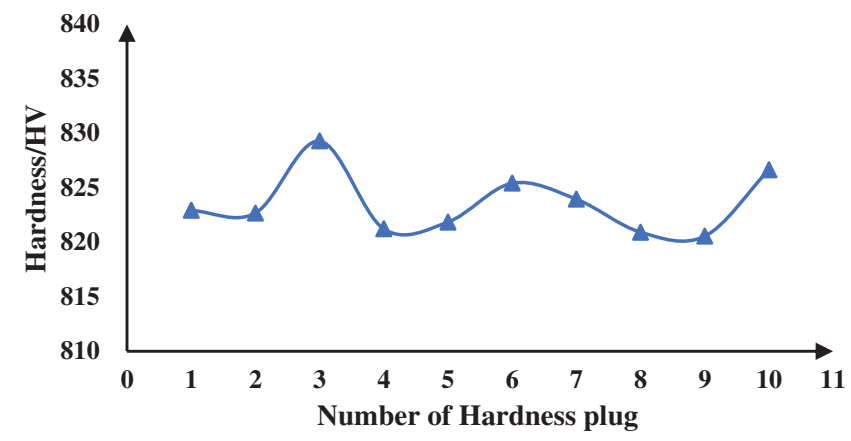

Figure 1: Measured value of hardness plug after quenching 
From the preceding data, it can be found that the hardness plug after quenching had very uniform hardness values, with a deviation within $\pm 10 \mathrm{HV}$, and the hardness of the experimental material met the requirements of $\mathrm{HV} \geq 800$.

The tempering test were carried out in the hardness plug tempering test in a constant temperature box, and the temperature was kept at $150^{\circ} \mathrm{C}$ to $450^{\circ} \mathrm{C}$ every $50^{\circ} \mathrm{C}$ for $2 \mathrm{~h}$ (the engine piston temperature was between $250^{\circ} \mathrm{C}$ and $300^{\circ} \mathrm{C}$, and the measurement point was increased by $275^{\circ} \mathrm{C}$ within this range), with air-cooled in the furnace. The measured data was shown in Table 2.

Table 2: Calibration of hardness test after quenching

\begin{tabular}{llllllll}
\hline $\begin{array}{l}\text { Tempering } \\
\text { temperature } /{ }^{\circ} \mathrm{C}\end{array}$ & \multicolumn{9}{c}{ Test hardness value/HV } & & $\begin{array}{l}\text { Average hardness } \\
\text { value/HV }\end{array}$ \\
\hline 150 & 684.5 & 685 & 680 & 680 & 683 & 680.5 & 683.2 \\
200 & 641.8 & 642 & 639 & 635 & 636 & 643 & 639.8 \\
250 & 610 & 616.1 & 614 & 614 & 614 & 614.1 & 613.7 \\
275 & 569.7 & 566 & 575.2 & 571.5 & 571.5 & 571.5 & 570.5 \\
300 & 523.5 & 517.1 & 528.3 & 528.3 & 523.5 & 521 & 523.5 \\
350 & 424.5 & 435.3 & 429.3 & 435.3 & 432.9 & 423.9 & 431.8 \\
400 & 390.4 & 386.3 & 395.6 & 390.4 & 398 & 398.6 & 393.2 \\
450 & 338 & 335 & 343 & 341 & 344.2 & 342 & 340.5 \\
\hline
\end{tabular}

According to the data in Table 2, a characteristic curve of hardness-tempering temperature was drawn, as shown in Fig. 2. It can be seen from Fig. 2 and Table 3 that the change basically met the requirements of a linear change and the characteristic was relatively good.

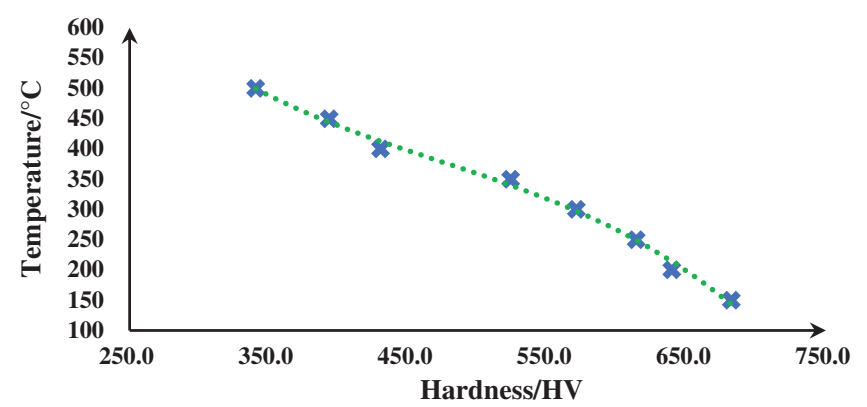

Figure 2: Numerical simulation of hardness-tempering temperature characteristic curve

Table 3: Error analysis of numerical simulation of curve

\begin{tabular}{llll}
\hline Test hardness value & Actual temperature value & Fit temperature value & Deviation \\
\hline 683.2 & 150 & 148.1 & $1.27 \%$ \\
639.8 & 200 & 204.6 & $-2.30 \%$ \\
613.7 & 250 & 249.6 & $0.16 \%$ \\
570.5 & 300 & 303.6 & $-1.20 \%$ \\
\hline & & & (Continued)
\end{tabular}




\begin{tabular}{llll}
\hline Table 3 (continued). & & & \\
\hline Test hardness value & Actual temperature value & Fit temperature value & Deviation \\
\hline 523.5 & 350 & 343.4 & $1.89 \%$ \\
431.8 & 400 & 403.3 & $-0.83 \%$ \\
393.2 & 450 & 446.5 & $0.78 \%$ \\
340.5 & 500 & 503.6 & $-0.72 \%$ \\
\hline
\end{tabular}

\subsection{Position of Piston Temperature Test and Engine Experiment}

The main parameters of the piston were shown in Table 4. In order to ensure the accuracy of the experimental measurement, 20 measurement points were selected, and the hardness plug was installed according to the piston solution structure, shown in Fig. 3.

Table 4: The main key parameters of the piston

\begin{tabular}{ll}
\hline Name & Parameter $/ \mathrm{mm}$ \\
\hline Piston diameter & 104 \\
Piston pin diameter & 24 \\
Piston skirt height & 65 \\
Piston oil hole diameter & 5 \\
\hline
\end{tabular}
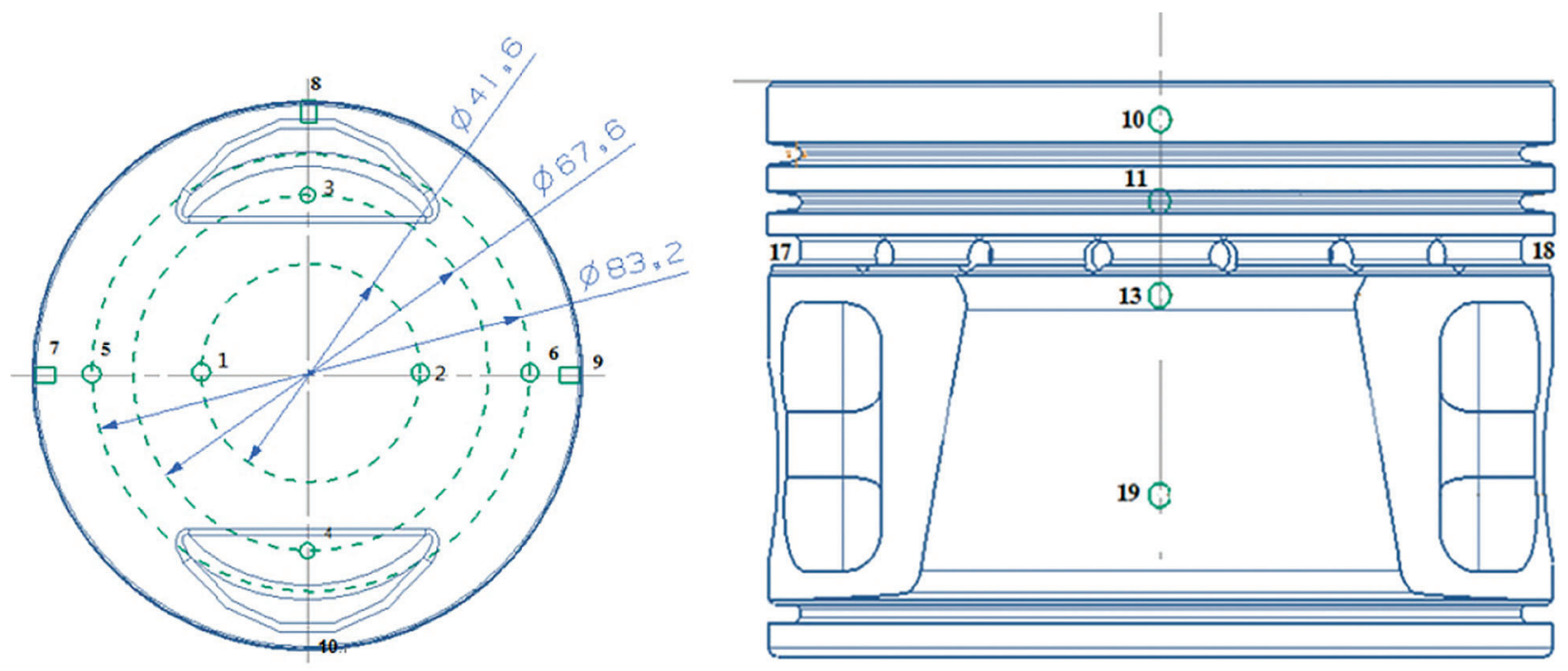

Figure 3: The location point of hardness plug on the side of the piston

The engine experiment of the piston temperature test was accomplished under certain conditions. The main parameters of the test conditions were shown in Table 5.

The temperature data under different working conditions between original piston and anodized piston was shown in the Figs. 4 and 5. It can be seen from the that under the conditions of maximum operating torque (as short for $\mathrm{T}_{\mathrm{tpmax}}$ ) and maximum operating power (as short for $\mathrm{P}_{\mathrm{emax}}$ ), most of the temperature 
values of the anodized piston were lower than those of the original piston, which indicated that the above process improvement had the effect of reducing the thermal load of the actual work of the piston.

Table 5: Test conditions of engine temperature experiment

\begin{tabular}{llll}
\hline Test conditions & $\mathrm{n}(\mathrm{r} / \mathrm{min})$ & Intake pressure $/ \mathrm{kpa}$ & $\mathrm{Pe} / \mathrm{kW}$ \\
\hline $\mathrm{A}-\mathrm{T}_{\text {tqmax }}$ & $1950 \pm 10$ & $88 \pm 2$ & 121 \\
$\mathrm{~B}-\mathrm{P}_{\mathrm{emax}}$ & $2250 \pm 10$ & $\mathrm{P}_{0}+10.7_{-1.3}^{+2.0}$ & 199 \\
\hline Note: $\mathrm{P}_{0}$ refers to the local external atmospheric pressure under standard conditions $(\mathrm{kpa})$.
\end{tabular}

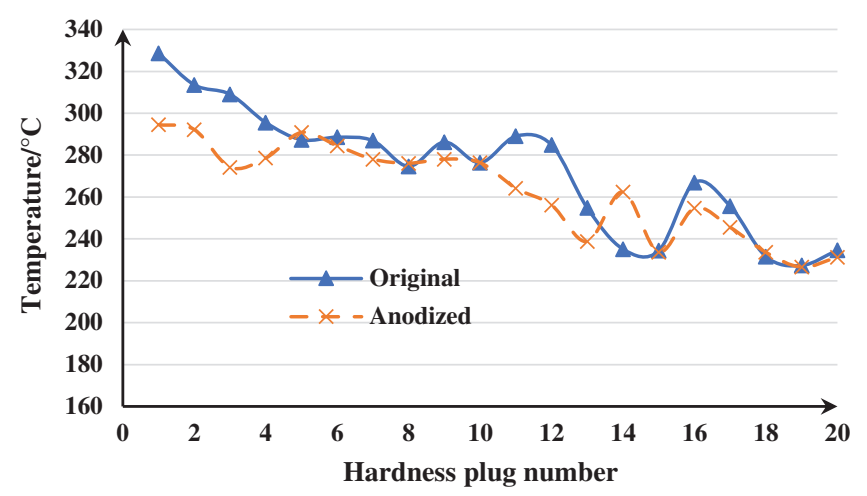

Figure 4: Temperature variation curves between Original piston and Anodized piston under $\mathrm{T}_{\text {tqmax }}$

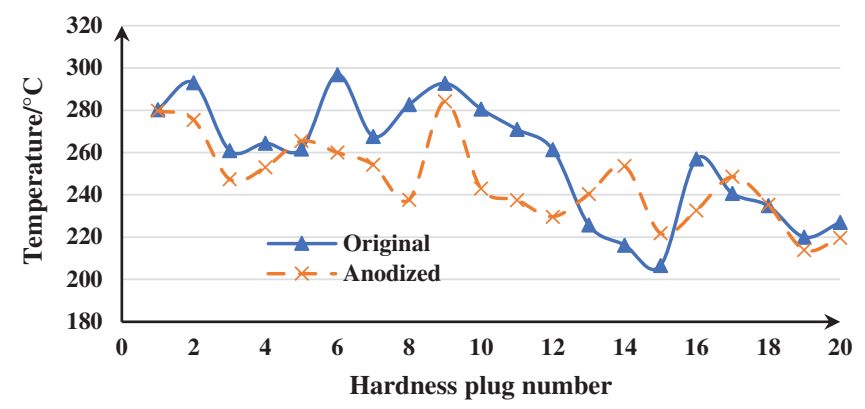

Figure 5: Temperature variation curves between Original piston and Anodized piston under $\mathrm{P}_{\mathrm{emax}}$

\section{Finite Element Model of Piston and Boundary Conditions of Simulation Analysis}

\subsection{Piston Material and Finite Element Model}

The piston material was forged aluminum $2 \mathrm{~A} 80$, the density was $2.77 * 10^{\wedge} 3 \mathrm{~kg} / \mathrm{m}^{3}$, the elastic modulus of its material properties was $72 \mathrm{Gpa}$, the Poisson's ratio was 0.33 , and the tensile strength was $375 \mathrm{Mpa}$. The thermal conductivity and linear expansion coefficient were shown in Table 6.

The finite element analysis software of this time was ABAQUS, which was mainly considered to be a set of powerful engineering simulation finite element software, which can solve problems of not only relatively simple linear analysis but also many complex nonlinear problems [5]. The finite element mesh model of the piston was shown in Fig. 6. The piston model used in this calculation was a second-order tetrahedral mesh cell in compliance with the requirements of finite element analysis. The finite element parameter information contained 91517 nodes and 53440 elements. 
Table 6: Material properties of piston

\begin{tabular}{|c|c|c|c|c|c|}
\hline \multirow{2}{*}{$\begin{array}{l}\text { The elastic } \\
\text { modulus } \\
(\mathrm{MPa})\end{array}$} & \multicolumn{2}{|c|}{$\begin{array}{l}\text { Thermal conductivity changes } \\
\text { with temperature }\end{array}$} & \multicolumn{2}{|c|}{$\begin{array}{l}\text { Linear expansion coefficient } \\
\text { changes with temperature }\end{array}$} & \multirow[t]{2}{*}{$\begin{array}{l}\text { Ultimate tensile } \\
\text { strength (MPa) }\end{array}$} \\
\hline & $\begin{array}{l}\text { Temperature } \\
\left({ }^{\circ} \mathrm{C}\right)\end{array}$ & $\begin{array}{l}\text { Thermal } \\
\text { conductivity } \\
\left(\mathrm{W} /\left(\mathrm{m} .{ }^{\circ} \mathrm{C}\right)\right)\end{array}$ & $\begin{array}{l}\text { Temperature } \\
\left({ }^{\circ} \mathrm{C}\right)\end{array}$ & $\begin{array}{l}\text { Linear expansion } \\
\text { coefficient }\left(10^{-6} /{ }^{\circ} \mathrm{C}\right)\end{array}$ & \\
\hline \multirow{5}{*}{72,000} & 25 & 146.5 & 20 & 21.8 & \multirow[t]{5}{*}{375} \\
\hline & 100 & 150.7 & 100 & 21.8 & \\
\hline & 200 & 159.1 & 200 & 23.9 & \\
\hline & 300 & 167.5 & 300 & 24.9 & \\
\hline & 400 & 171.7 & I & / & \\
\hline
\end{tabular}

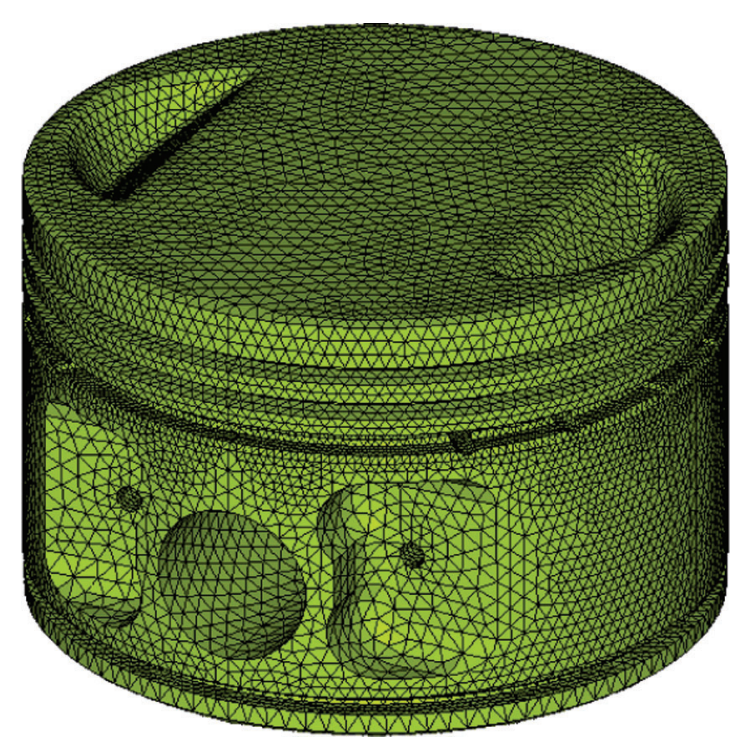

Figure 6: Finite element mesh model of anodized piston

\subsection{Boundary Conditions of Simulation Analysis}

\subsubsection{Boundary Conditions of the Top of the Piston and Internal Heat Transfer}

According to the theory of periodic transient temperature fluctuations [6], the temperature of the top of the piston decreased rapidly along the normal direction of the top of the piston. Temperature fluctuation occurred only on the 1 2 mm surface of the piston top. Under the general specific working conditions, the temperature field on the top of the piston was defined as the stable Temperature field. According to the gas pressure of the engine acting on the piston crown and the volume of the cylinder [7], the instantaneous temperature of the cylinder was calculated using Eq. (1).

The relationship between the gas pressure in the cylinder and the crank angle was shown in Fig. 7 .

$$
T_{g}=\frac{P_{g} V}{m R}
$$




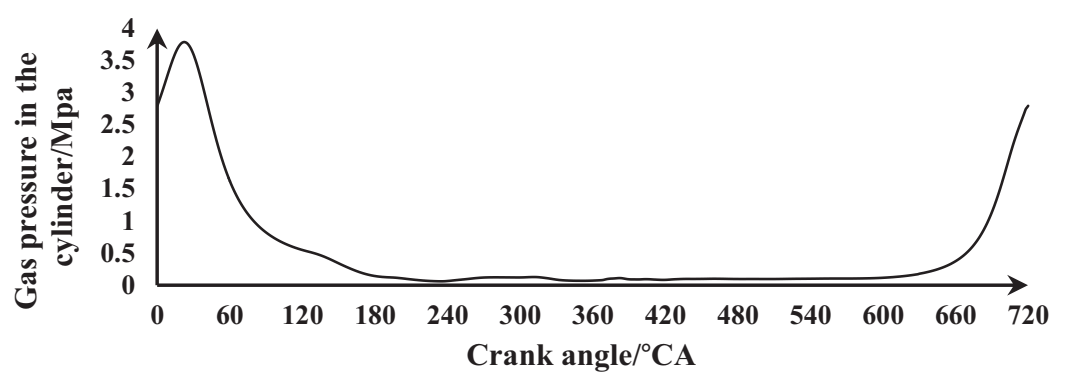

Figure 7: Variation curve of gas pressure in cylinder along with crank angle

The instantaneous heat release coefficient was calculated using the Eickelberg formula [8], scilicet

$a_{g}=7.8 \sqrt[3]{u_{m}} \sqrt{T_{g} P_{g}}$

In the formula: $u_{m}$ represents the average speed of the piston; $T_{g}$ represents the instantaneous temperature of the gas $(\mathrm{K}), P_{g}$ represents the instantaneous pressure of the gas $(\mathrm{Mpa})$.

The internal heat transfer coefficient of the piston was affected by the temperature at the top of the piston and the airflow movement of the crankcase [9], which was generally expressed by Eq. (3)

$a_{\text {in }}=\frac{\left(T_{1}-T_{2}\right) \mathrm{k}}{\left(T_{1}-T_{\text {in }}\right) \sigma}$

In the formula: $T_{1}, T_{2}, T_{\text {in }}$ represent the temperature of the top of the piston, the temperature of the bottom of the piston and the temperature of the crankcase gas, respectively; $\mathrm{k}, \sigma$ respectively represent the thermal conductivity of the piston, the thickness of the top of the piston; $a_{i n}$ is for gas heat exchange coefficient between piston and crankcase.

\subsubsection{Boundary Conditions of Heat Transfer between the Piston and Cylinder Wall}

The heat transfer coefficients of the piston fire bank, piston ring groove and piston group were difficult to determine accurately [10]. Generally, empirical formulas were used to resolve the problem. Fig. 8 illustrated the heat transfer model. The heat transfer coefficient was affected by factors such as oil layer, piston ring, gas layer, and cylinder jacket thickness. The heat transfer coefficient can be shown in Table 7.

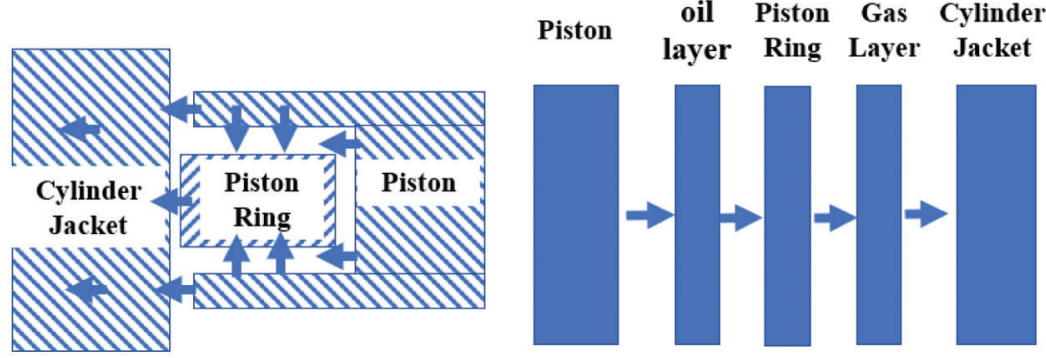

Figure 8: Thermal transfer model of piston and cylinder wall

The boundary conditions for the simulation calculation of piston heat transfer under various operating conditions were shown in Table 7. 
Table 7: Boundary conditions for the simulation calculation of piston thermal transfer under two operating conditions

\begin{tabular}{llll}
\hline \multicolumn{2}{c}{ Regional boundary } & Ambient temperature $/{ }^{\circ} \mathrm{C}$ & $\begin{array}{l}\text { Convection thermal transfer } \\
\text { coefficient } /\left[\mathrm{W} /\left(\mathrm{m}^{2} \cdot{ }^{\circ} \mathrm{C}\right)\right]\end{array}$ \\
\hline Top land & & $165 / 180$ & $350.3 / 350.3$ \\
Other belt & $150 / 160$ & $400.6 / 400.6$ \\
Gas ring groove & up \& down & $145 / 160$ & $300.7 / 300.7$ \\
& bottom & $146 / 150$ & $250.1 / 250.1$ \\
Oil ring groove & up \& down & $145 / 150$ & $300.7 / 300.7$ \\
(original) & bottom & $146 / 150$ & $250.1 / 250.1$ \\
Oil ring groove & up \& down & $156.5 / 145$ & $311.2 / 311.2$ \\
(original) & bottom & $158 / 145$ & $255 / 255$ \\
Piston skirt & & $133 / 140$ & $300.6 / 300.6$ \\
Piston pin hole & & $132 / 140$ & $270.3 / 270.3$ \\
Inner & up & $97 / 100$ & $409.6 / 430.9$ \\
& down & $96 / 100$ & $521.7 / 600.3$ \\
\hline
\end{tabular}

\section{Comparative Study of Computer Simulation and Experiment}

\subsection{Piston Thermal Load Calculation and Experiment}

Figs. 9 and 12 illustrated the comparison curves between computer simulation and experiment under different working conditions. It can be seen from Figs. 9 to 12 that computer simulation was in highly agreement with the experimental data, and the error rate was less than $5 \%$, which effectively validated the conclusion that the least squares method and the computer simulation have certain reliability and meet the requirements of engineering applications. It is quite normal for the difference between experiment and simulation. The possible reasons for the difference included the unstable test conditions, inaccurate experimental data, differences in boundary conditions measurement error and so on. However, from Fig. 11, it can be inferred that the change trend of experiment and simulation had a high degree of consistency, which reflected from the other side that the simulation had a certain credibility.

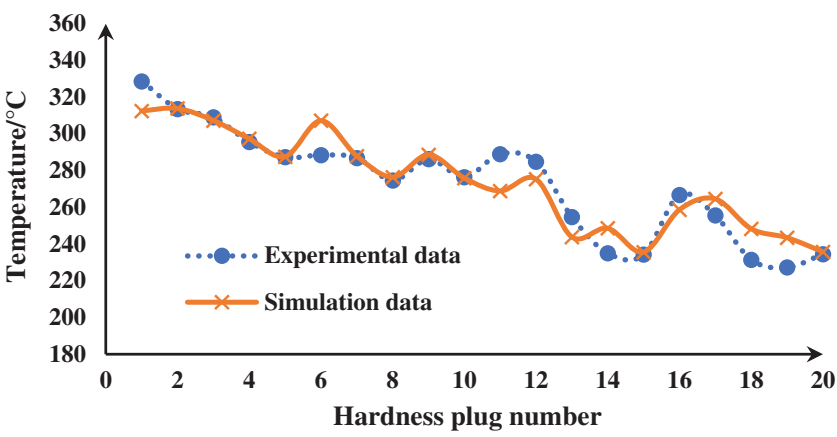

Figure 9: Comparison of experiment and simulation under $\mathrm{T}_{\mathrm{tqmax}}$ condition of the original piston 


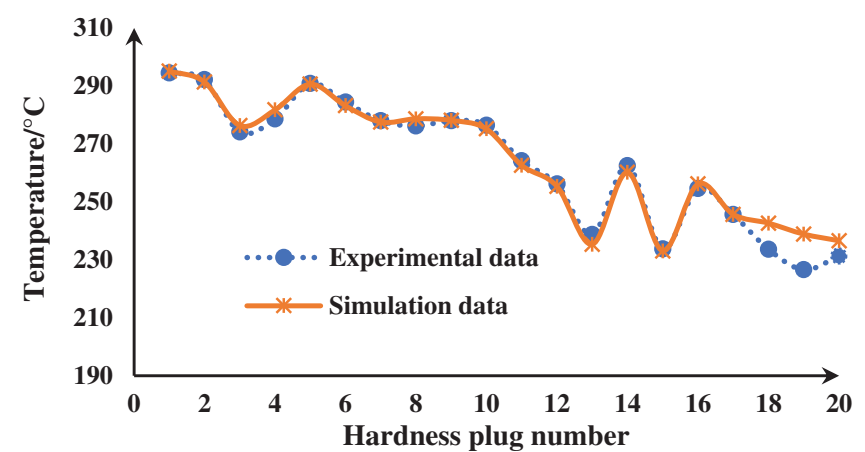

Figure 10: Comparison of experiment and simulation under $\mathrm{T}_{\text {tqmax }}$ condition of the anodized piston

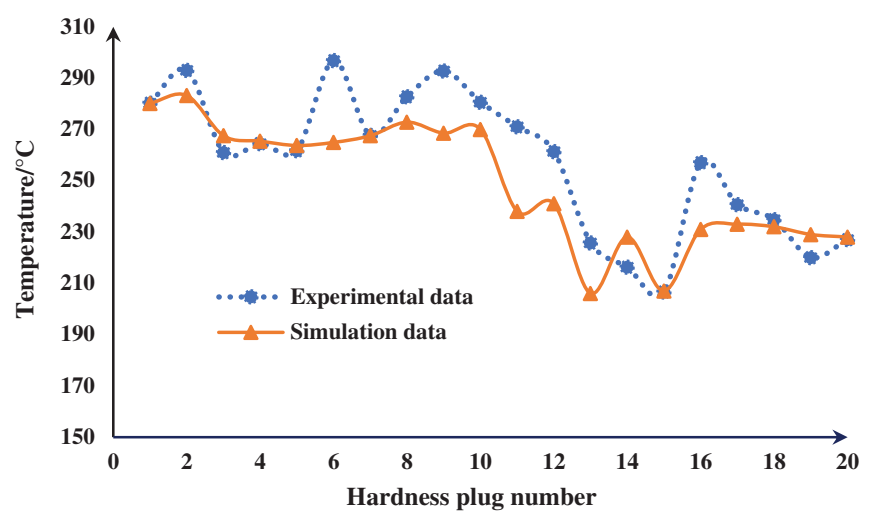

Figure 11: Comparison of experiment and simulation under $\mathrm{P}_{\mathrm{emax}}$ of the original piston

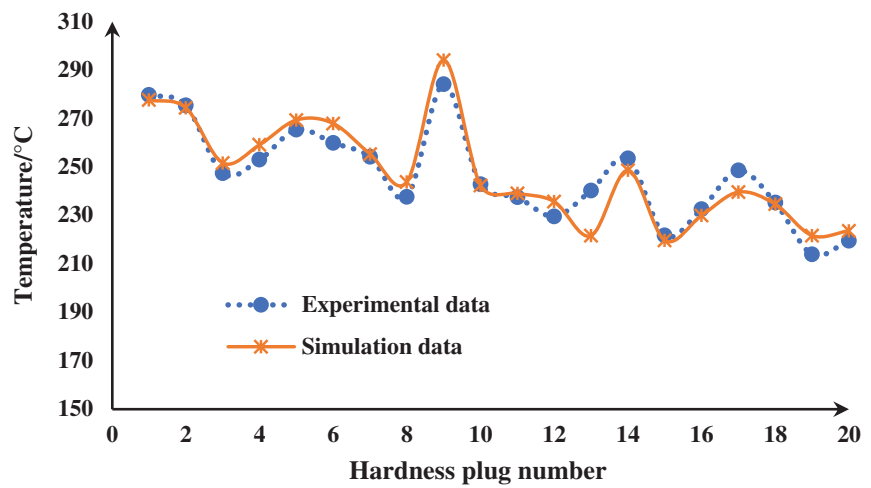

Figure 12: Comparison of experiment and simulation under $\mathrm{P}_{\mathrm{emax}}$ condition of the anodized piston

Through computer simulation analysis of the piston temperature field data, as shown in Figs. 13-16 above, it can be seen that under the maximum torque condition, the temperature after optimization was $265.3^{\circ} \mathrm{C}$, which was $51.9^{\circ} \mathrm{C}$ lower than the temperature before optimization $\left(317.2^{\circ} \mathrm{C}\right)$, and the decrease rate was $16.36 \%$. Under the maximum power condition, the temperature after optimization is $290.9^{\circ} \mathrm{C}$, which was $16.6^{\circ} \mathrm{C}$ lower than the temperature before optimization $\left(307.5^{\circ} \mathrm{C}\right)$, and the decrease rate was $5.4 \%$. From the above simulation, it can be seen that by using the anodizing process, the maximum temperature of the piston can be reduced effectively no matter it is the maximum torque condition or the maximum power condition. 

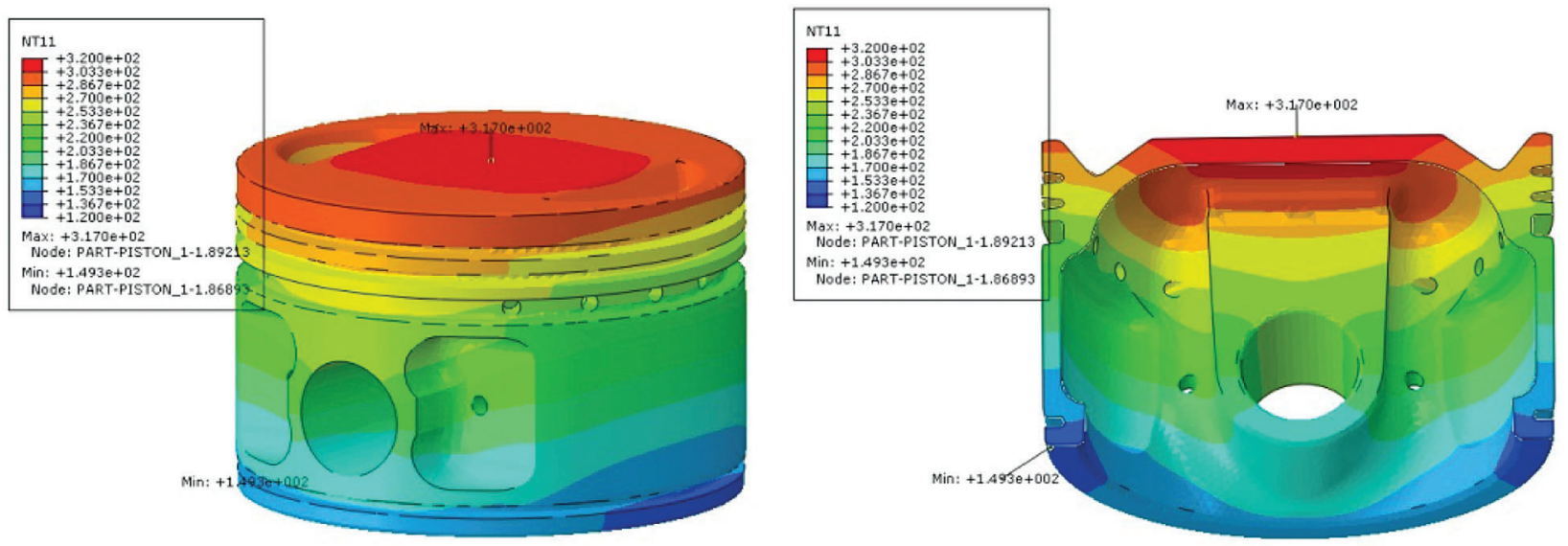

Figure 13: Cloud diagram of the simulated temperature field under $T_{\text {tqmax }}$ of the original piston
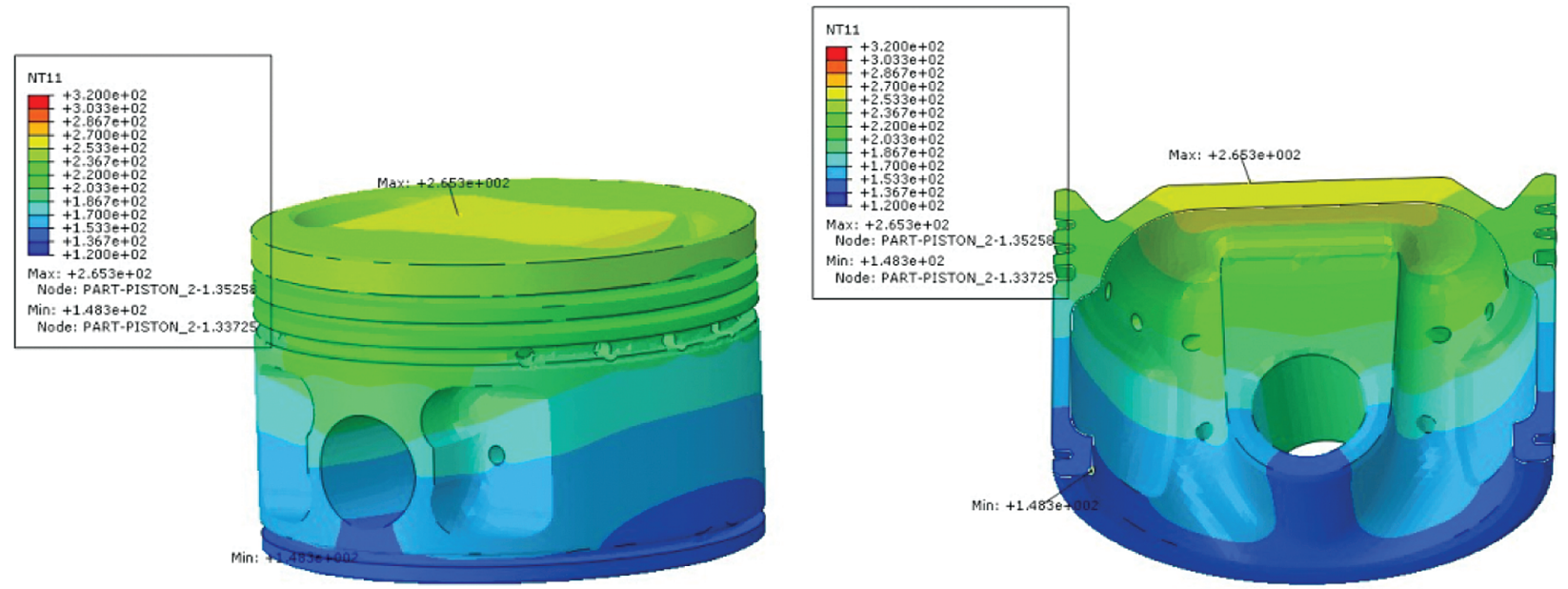

Figure 14: Cloud diagram of simulated temperature field under $T_{\mathrm{tqmax}}$ of the anodized piston
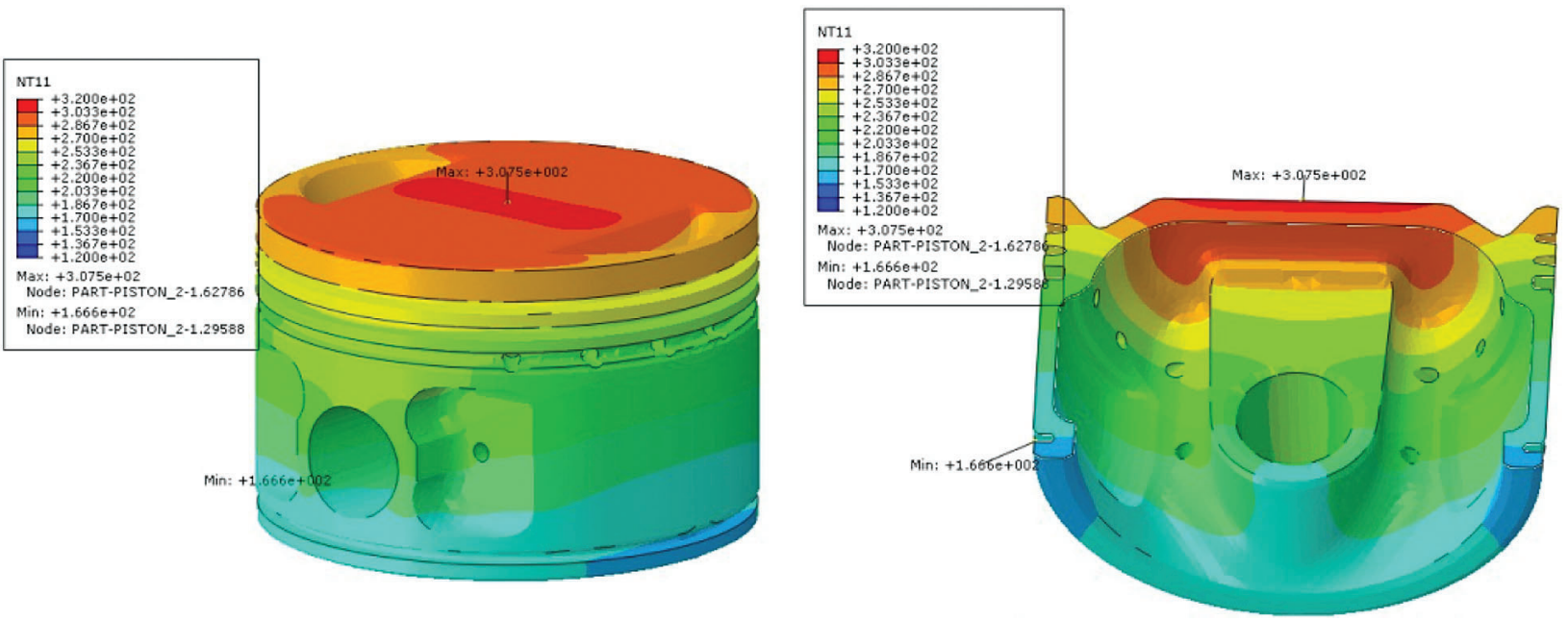

Figure 15: Cloud diagram of the simulated temperature field under $\mathrm{P}_{\mathrm{emax}}$ of the original piston 

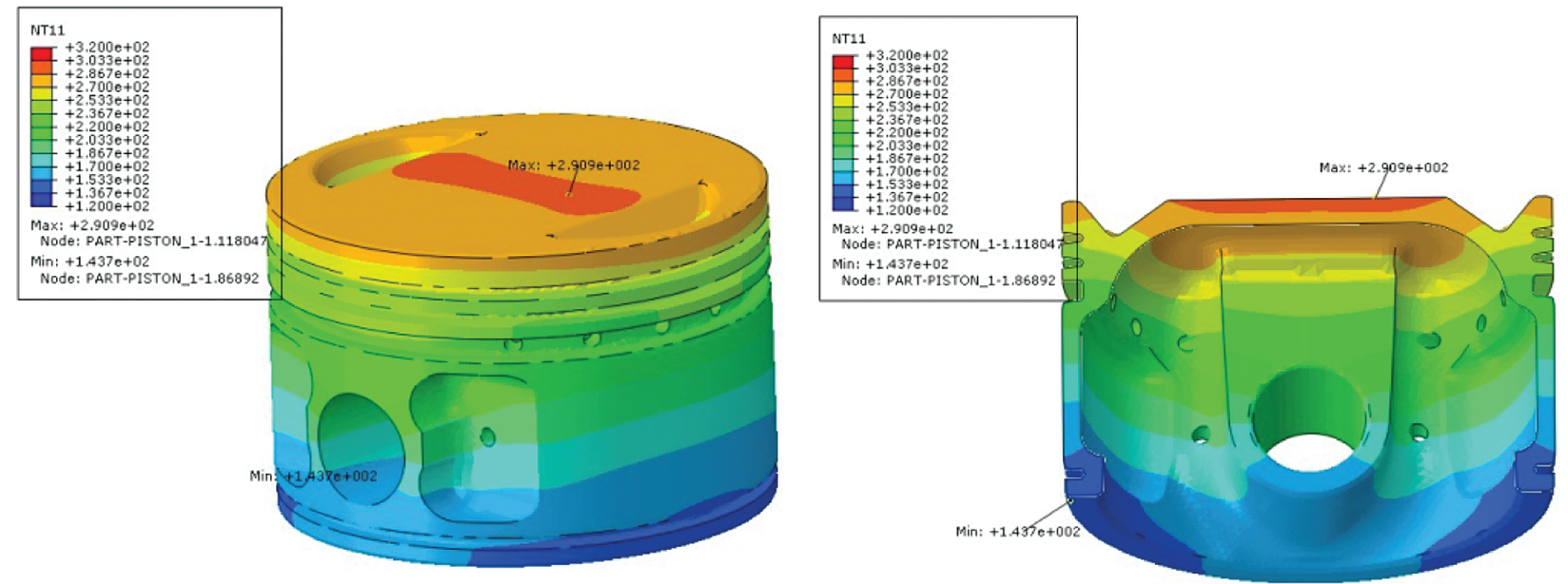

Figure 16: Cloud diagram of the simulated temperature field under $\mathrm{P}_{\mathrm{emax}}$ of the anodized piston

\subsection{Analysis of Piston Thermal Stress}

To meet the strength requirements of the material at high temperature, the thermal stress of the piston temperature field before and after optimization should be within $50 \mathrm{Mpa}$ [11]. Figs. 17 to 20 had be shown the thermal stress analysis result between the original piston and the anodized piston under two different conditions. It can be seen from the cloud diagram that under either the $\mathrm{T}_{\text {tqmax }}$ condition or the $\mathrm{p}_{\text {emax }}$ condition, the large thermal stress of the region after optimization was significantly reduced compared with before optimization, especially at the top inside the piston.
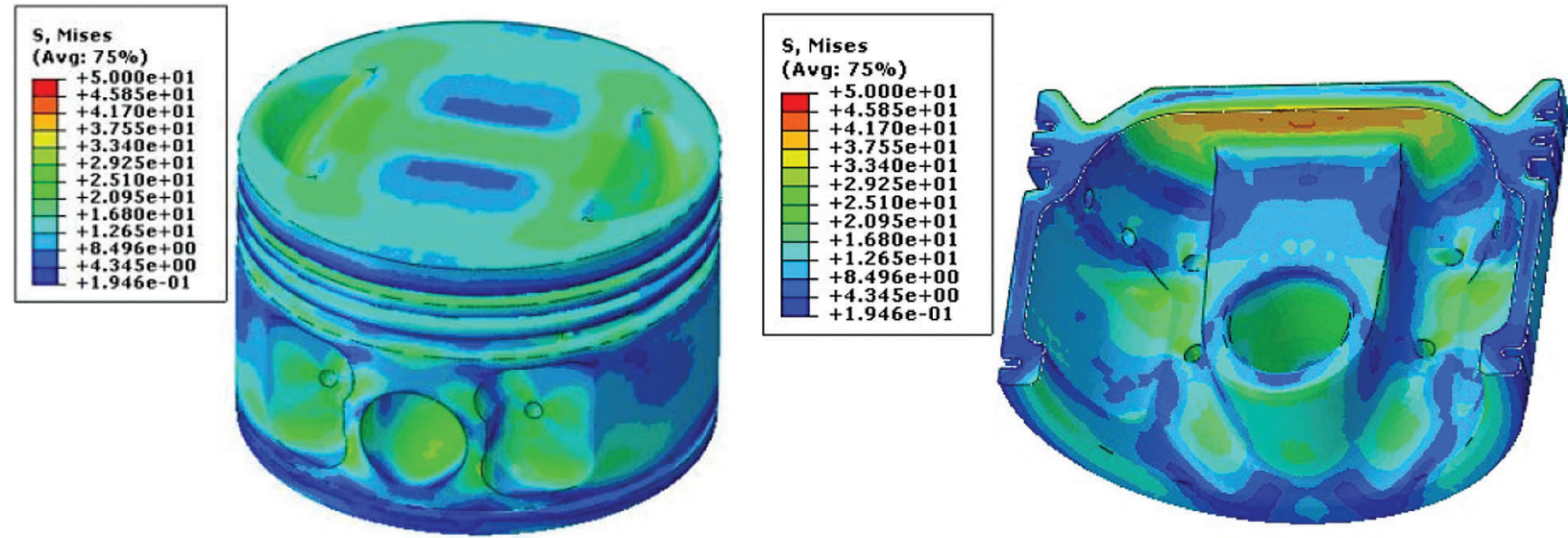

Figure 17: Thermal stress cloud under $T_{\text {tqmax }}$ of the original piston

\section{Calculation and Analysis of Fatigue under Typical Working Conditions}

The piston with aluminum alloy material had highly dispersed strength. Generally, the conservative Goodman line was used, and the Haigh diagram is used to solve the fatigue strength [12]. According to the calculation results of the piston strength, the pistons of the master cylinder original and modified in the maximum continuous condition were selected for fatigue safety factor evaluation. 

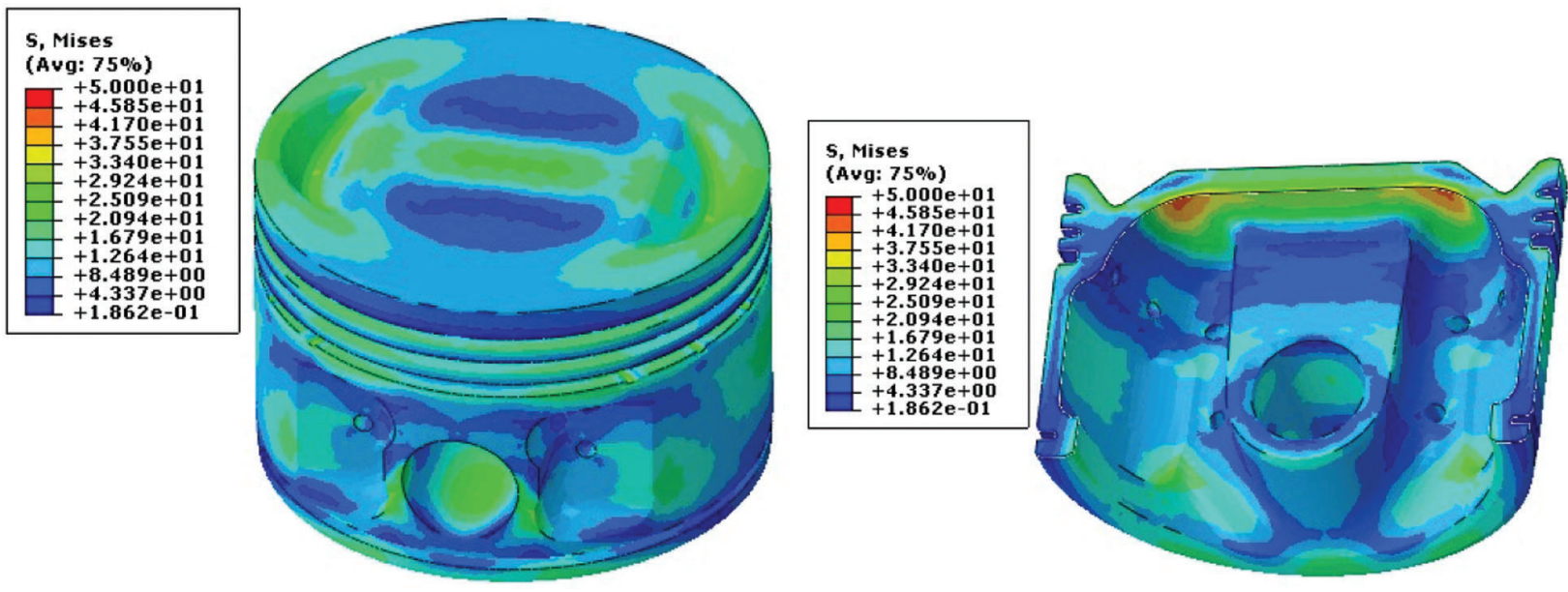

Figure 18: Thermal stress cloud under $T_{\text {tqmax }}$ of the anodized piston
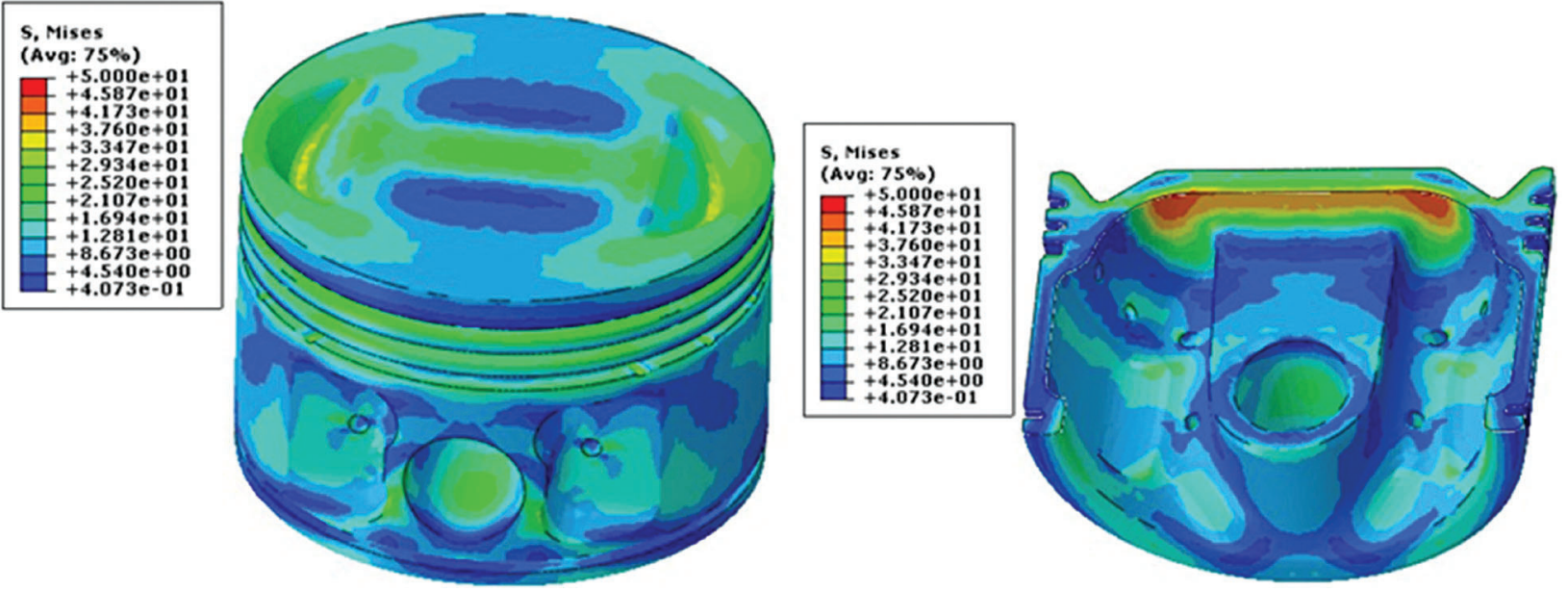

Figure 19: Thermal stress cloud under $P_{e m a x}$ of the original piston
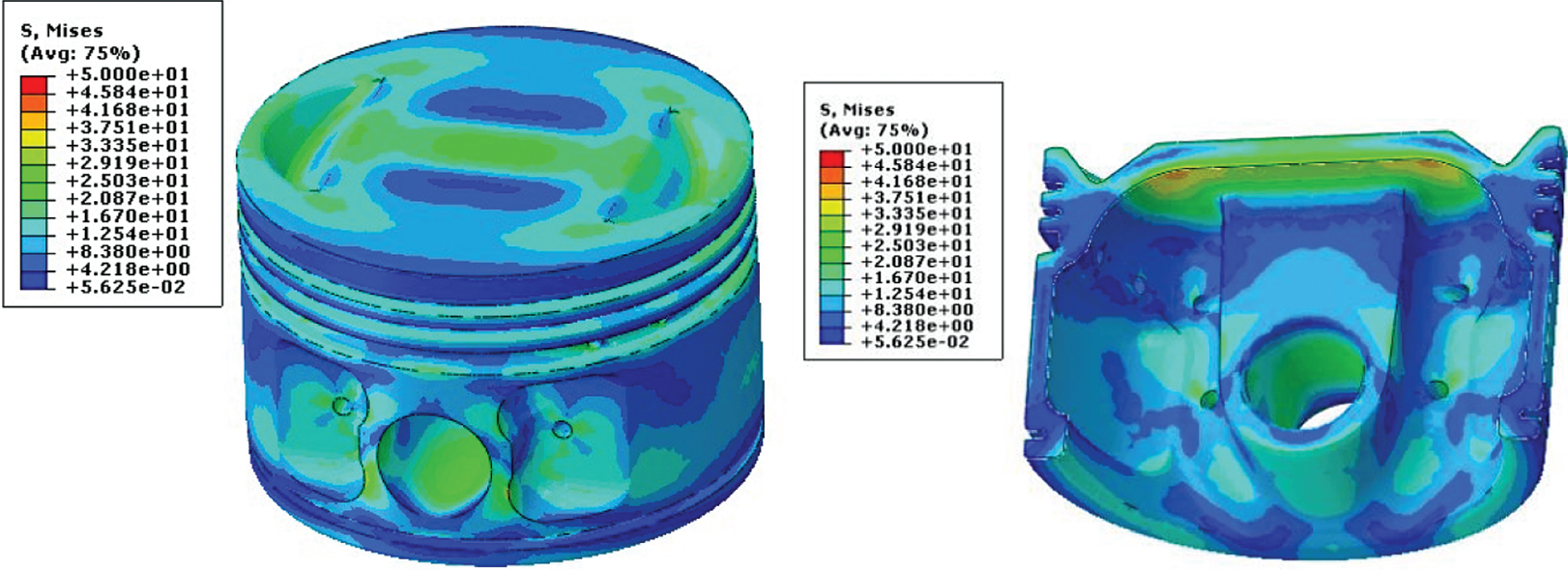

Figure 20: Thermal stress cloud under $\mathrm{P}_{\mathrm{emax}}$ of the anodized piston 
The safety factor of the original piston above 1.8 was $98.61 \%$, and the safety factor of modified piston above 1.8 was $99.13 \%$. It can be seen that the safety factor was improved, but the results are not obvious. It can be seen from Figs. 21 and 22, the lower safety factor is mainly distributed at the edge of the oil return hole, the root of the piston cavity pin seat and the contact surface on the piston pin hole for original, as shown in Fig. 21. The lower safety factor is mainly distributed in the area where the root of the piston pin seat of the inner cavity intersects the weight reduction hole for modified piston, as shown in Fig. 22. The safety factor of the piston both original and modified can meet the requirements of material fatigue strength.

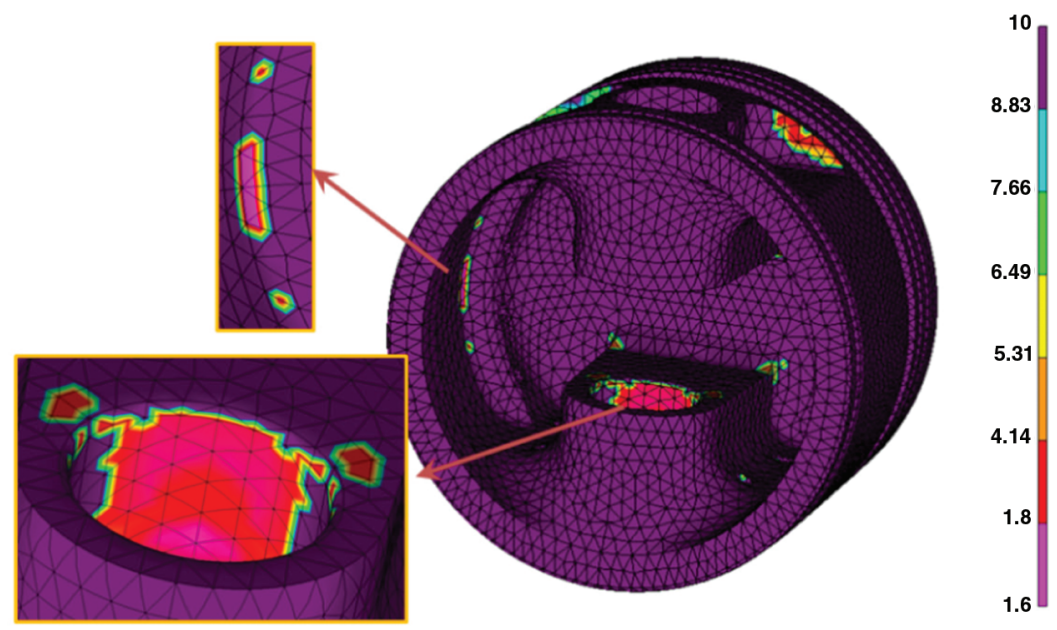

Figure 21: The distribution of safety factors of the inner cavity of the original piston of the master cylinder under the maximum continuous

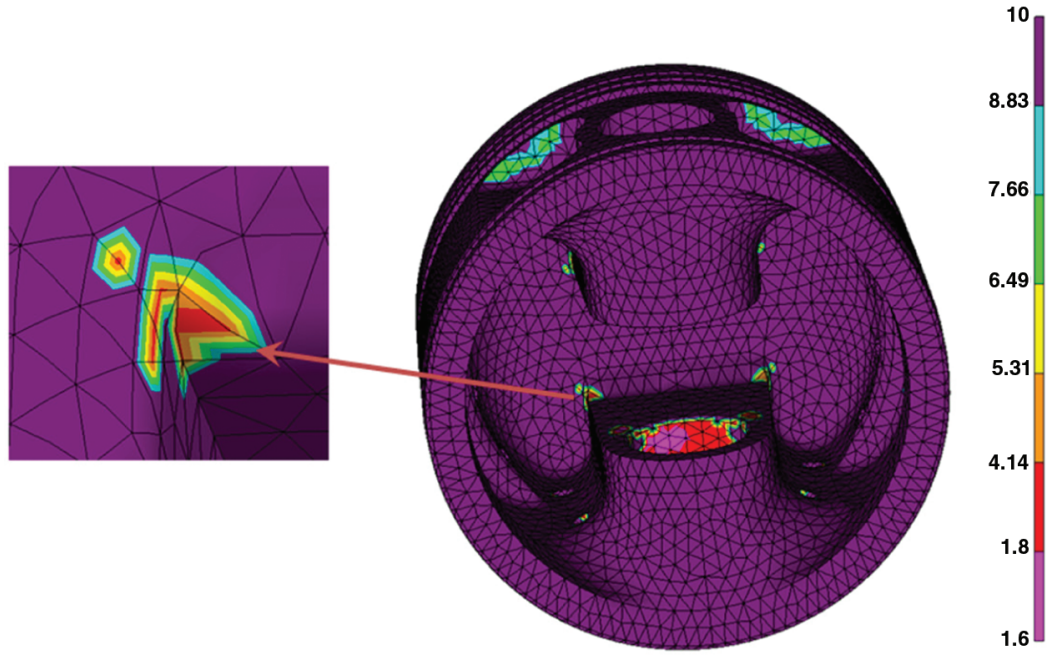

Figure 22: The distribution of safety factors of the inner cavity of the anodized piston of the master cylinder under the maximum continuous

\section{Conclusion}

In this paper, the temperature field of the anodized piston is studied by means of hardness plug temperature test and numerical fitting method. Through a comparison between the CAE simulation and experimental test, combined with the heat transfer boundary conditions of the piston, and under the 
condition that the calculation error is less than 5\%, the temperature field distribution of the original piston and the anodized piston under the maximum torque and the maximum power conditions is obtained.

The comparison between simulation and experiment shows that the maximum temperature of the anodized piston is $16.36 \%$ and $5.4 \%$ lower than the original piston under the maximum torque condition and the maximum power. The thermal stress of the temperature field of both pistons is within $50 \mathrm{Mpa}$, which meets the strength requirements of the material at high temperature. However, the area of thermal stress of the anodized piston is significantly lower than that of the original piston, especially at the top of the piston. Combined with the fatigue analysis data, it can be seen that the safety factor of the anodized piston greater than 1.8 is $99.13 \%$. The anodizing process improves the surface mechanical properties to a certain extent and has a certain thermal insulation effect, which plays a positive role in reducing the piston temperature and thermal stress as well as in improving the reliability and life of the piston.

Acknowledgement: My gratitude would go to my dear family for their love and support throughout the years. I would also like to express my sincere gratitude to colleagues for their help and understanding during the experimental process of my thesis and for helping me to solve my difficulties.

Funding Statement: The authors received no specific funding for this study.

Conflicts of Interest: The authors declare that they have no conflicts of interest to report regarding the present study.

\section{References}

1. Caputo, S., Millo, F., Boccardo, G., Piano, A., Cifali, G. et al. (2019). Numerical and experimental investigation of a piston thermal barrier coating for an automotive diesel engine application. Applied Thermal Engineering, 162, 114-233.

2. Jalali, H., Abbassi, H. (2020). Analysis of the influence of viscosity and thermal conductivity on heat transfer by $\mathrm{Al}_{2} \mathrm{O}_{3}$-water nanofluid. Fluid Dynamics \& Materials Processing, 16(2), 181-198.

3. Lu, Y., Zhang, X., Xiang, P., Dong, D. (2017). Analysis of thermal temperature fields and thermal stress under steady temperature field of diesel engine piston. Applied Thermal Engineering, 113, 796-812.

4. Zya, B., Kh, A., Rong, L. B. (2019). Enhanced high-temperature thermal fatigue property of aluminum alloy piston with Nano PYSZ thermal barrier coatings. Journal of Alloys and Compounds, 790, 466-479.

5. Kriraa, M., Souhar, K., Achemlal, D. (2020). Fluid flow and convective heat transfer in a water chemical condenser. Fluid Dynamics \& Materials Processing, 16(2), 199-209.

6. Kim, G., Kang, Y. C., Woo, J., Kim, J. H., Yeon Cho, J. (2020). Efficient prediction of the temperature history of a hypersonic vehicle throughout the mission trajectory with an aerodynamic thermal load element. International Journal of Aeronautical and Space Sciences, 21(2), 363-379.

7. Wang, M., Pang, J. C., Zhang, M. X., Liu, H. Q., Li, S. X. et al. (2018). Thermo-mechanical fatigue behavior and life prediction of the Al-Si piston alloy. Materials Science \& Engineering: A, 715, 62-72.

8. Selvam, R., Prakash, S., Gokulnath, R., Lillymercy, J. (2019). Experimental investigation of castor oil and methanol powered DI-CI engine with thermal barrier coated piston. International Journal of Vehicle Structures \& Systems, 11, 466-470.

9. Shu, X., Ren, M. (2020). On the design and optimization of a clean and efficient combustion mode for internal combustion engines through a computer NSGA-II algorithm. Fluid Dynamics \& Materials Processing, 16(5), 1019-1029.

10. Triveni, M., Panua, R. (2018). Numerical study of natural convection in a right triangular enclosure with sinusoidal hot wall and different configurations of cold walls. Fluid Dynamics \& Materials Processing, 14(1), 1-21.

11. Hoche, F. X., Naze, L., Remy, L., Kster, A. et al. (2021). Effect of thermomechanical fatigue on precipitation microstructure in two precipitation-hardened cast aluminum alloys. Metallurgical and Materials Transactions A, 52, 3232-3246.

12. Totaro, P., Khusid, B. (2021). Multistep anodization of 7075-T6 aluminum alloy. Surface and Coatings Technology, 421(2), 127407. 